\title{
IMAGINARIOS DE LA FUNCIÓN ÉTICA Y EL SENTIDO COMÚN EN LA ADMINISTRACIÓN DEPORTIVA
}

\author{
IMAGINARIES OF THE ETHICAL FUNCTION AND COMMON SENSE IN SPORTS \\ ADMINISTRATION
}

IMAGINÁRIOS DA FUNÇÃO ÉTICA E O SENTIDO COMUM NA ADMINISTRAÇÃO ESPORTIVA

Andrés Castiblanco Roldán ${ }^{1}$

\section{Resumen}

\begin{abstract}
Si el sentido común identifica a la función ética con la cívica y la urbanidad, así como con el leve peso de un sinnúmero de normas que indican lo que es bueno y lo que es malo, confundiéndola incluso con la moral, es necesario examinar cómo está desarrollándose su concepción en el avance profesional de la administración deportiva. El presente artículo aborda una reflexión que establece un diálogo interdisciplinario entre las ciencias humanas (antropología, sociología, psicología y filosofía) con este propósito. Primero, se tratan referencias teóricas acerca del imaginario, la ética y el sentido común para llegar a una indagación sobre los imaginarios de la función ética en las escuelas de formación, los institutos, clubes y cajas de compensación en cuanto escenarios donde se ejerce la gestión y administración deportiva. La conclusión de este artículo da con que lo lúdico y lo deportivo, desde su función administrativa y de gestión, ha de servir como óptica de administrar y operar para el deporte.
\end{abstract}

Palabras clave: función ética; imaginario; sentido común; administración; deporte

\section{Abstract}

If common sense associates ethics with civics and civility, as well as with the slight weight of a myriad of norms that indicate what is good and what is bad (even mistaking it for morality), we need to examine how it is being conceived in the professional progress of sports administration. The article opens an interdisciplinary dialogue between the human sciences (anthropology, sociology, psychology, and philosophy) for this purpose. First, we discuss theoretical references about the imaginary, ethics and common sense, followed by an inquiry about the imaginaries of the ethical function in training schools, institutes, clubs, and family benefit funds as scenarios where sports management and administration is practiced. The article concludes that entertainment and sport must, from their administrative and management function, serve as an optic of managing and operating for the sport.

Keywords: ethical function; imaginary; common sense; administration; sports

\footnotetext{
* Candidato a Doctor en Ciencias Humanas y Sociales Universidad Nacional de Colombia. Licenciado en Ciencias Sociales y Maestro en Investigación Social interdisciplinaria. Editor de la revista Esfera. Profesor Asociado Facultad de Ciencias y Educación Universidad Distrital Francisco José de Caldas. Correo electrónico: geoandes@hotmail.com
} 
Se o sentido comum identifica a função ética com a cívica e a urbanidade, assim como com o leve peso de um sem-número de normas que assinalam o que é bom e o que não é, confundindo-a com a moral, é preciso examinar como está se desenvolvendo sua concepção no avanço profissional da administração esportiva. 0 presente artigo aborda uma reflexão que estabelece um diálogo interdisciplinar entre as ciências humanas (antropologia, sociologia, psicologia e filosofia) com esse propósito. Primeiro, abordam-se referências teóricas acerca do imaginário, a ética e o sentido comum para indagar sobre os imaginários da função ética nas escolas de formação, os institutos, clubes e outras instituições onde existe a gestão e administração esportiva. A conclusão do artigo é que o lúdico e o esportivo, desde sua função administrativa e de gestão, deve servir como perspectiva de administrar e operar para o esporte.

Palavras chave: função ética; imaginário; sentido comum; administração; esporte

Fecha de recepción: 22 de julio de 2016

Fecha de aprobación: 4 de febrero de 2017

Para citar este artículo:

Castiblanco, A. (2017). Imaginarios de la función ética y el sentido común en la administración deportiva. Lúdica Pedagógica, (25), 145-156. 


\section{EL IMAGINARIO SOCIAL Y EL SENTIDO COMÚN COMO CONSTITUTIVOS DE LA FUNCIÓN ÉTICA}

Lo imaginario

La ética no se presenta como puro basamento abstracto o simbólico, su existencia reposa sobre los actos y las relaciones sociales donde existen consensos o conflictos frente a la resolución de las trabas o dificultades en las formas de convivencia de las comunidades. De esta forma, el acto ético evoca imaginaciones que dan cuenta de representaciones que, cuando predominan en el colectivo, se transforman en normas o patrones que rigen los grupos y el desarrollo en su entorno.

Cornelio Castoriadis (1989) afirma que:

Lo imaginario afecta los modos de simbolizar de aquello que conocemos como realidad y esta actividad se cuela en todas las instancias de nuestra vida social; siendo este concepto la capacidad de hacer surgir como imagen algo que no es ni que fue. (p. 108).

La consolidación de lo simbólico surge desde unas premisas heredadas de la tradición; el habitar de los hombres en los espacios implica una relación directa entre ellos, los elementos y la formación de un conjunto de referencias para distinguirlos y apropiarlos, entonces el imaginario brota como la lava de un volcán cuando se materializa en los escenarios de la vida humana, mostrando a los ojos del intérprete que las significaciones sociales, antes de fluir hacia la realidad, son un magma de sentidos. "El simbolismo presupone la capacidad imaginaria, ya que presupone la capacidad de ver en una cosa lo que no es, de verla otra de lo que es" (Castoriadis, 2003, p. 5).

En esta forma, interactúa lo simbólico preestablecido con la realidad que se impone al individuo, determinando la calidad de las relaciones interpersonales tanto con la familia como con aquellos donde no existe lazo afectivo; en dicha visión, prima la relación entre las formas psíquicas y el sistema social, que se puede relacionar con los análisis emitidos por Fromm (1997) desde la escuela psicoanalítica.

Para el antropólogo francés Gilbert Durand (2000), la cuestión es un poco diferente: se asume la existencia de un Homo simbolicus, que se diferencia del biológico Sapiens sapiens por su manejo de los signos y el comienzo del dominio de las relaciones a través de las significaciones, "los ritos funerarios y la elaboración de artefactos para los muertos en las poblaciones de los primeros tiempos" (p. 68), la comunicación se dirige por caminos que desde lo primitivo decodifican formas de entendimiento entre el grupo. Esta visión es interesante y se puede yuxtaponer a la de Castoriadis por el carácter inconsciente e instintivo que Durand le asigna a la formación de las estructuras de sentido en las culturas.

Lo icónico prevalece en esta visión, las nociones que hace la sociedad de sus lugares y sus gentes se enfocan en una serie de imágenes que emergen de la ilusión y la imaginación colectiva, universos simbólicos en términos de Cassirer (1983), que se transmiten y modifican a través del gesto, el cuerpo y la palabra. De hecho, es importante mirar que en los contextos actuales el espacio comunicativo con la gestión persuasiva de la tecnología publicitaria, es fuente de imágenes y actos que inspiran una serie de ensoñaciones llevando a las sociedades a defender y conservar la apariencia como andamiaje simbólico sobre la realidad.

La proximidad y la vecindad en los espacios laborales y afectivos comprometen la construcción de sentido, formando las representaciones éticas colectivas, la cual se centra sobre estas relaciones sociales y la constitución de la mentalidad alrededor de los acontecimientos íntimos, los cuales son revisados bajo la visión de la moral y la prudencia; en cierta medida, es adentrarse a lo soterrado de los pobladores y sus intenciones y realidades.

De esta forma, el imaginario es obra de las relaciones entre hombres y su influencia en referencia a su materialización como actos humanos, se imprime no solo en los roles de la vida diaria, sino en las condiciones que son creadas por las sociedades sobre las formas de interpretación de las relaciones interpersonales. Códigos de ética y normas morales que regularizan los impulsos que hacen posible la convivencia ciudadana.

En el control y la regulación de los actos organizacionales en el deporte, se busca precisamente que exista un equilibrio entre un recurso humano eficiente y adecuadamente funcional y la disposición sobre lo material en relación con equipos y presupuestos en el desarrollo de proyectos deportivos. Para tales fines, en este campo se han venido desarrollado sistemas de normas disciplinarias como el Decreto 2845 de 1984 (posteriormente renovado hacia 1993). En esta ley y en las disposiciones reglamentarias de estas normas se 
ocupan y cubren las formas estatutarias de los clubes deportivos, ligas, divisiones profesionales y federaciones deportivas colombianas, cuando se trate de actividades o competiciones de carácter nacional e internacional o afecte a deportistas, dirigentes, personal técnico, científico, auxiliar y de juzgamiento que participen en ellas (Ley 49 de 1993).

\section{El mito, el lenguaje y la estética-arte como ejes y formas simbólicas de la función ética}

Cuando se habla de la función ética, se está recurriendo a todos los elementos que proveen de sentido a las acciones de las sociedades, las formas legales y legítimas que regulan el comportamiento y la construcción significativa que las formaliza ante la realidad. En este panorama, la importancia del lenguaje otorga signos a los hechos, las formas corporales, la importancia de regular el deporte nace desde la misma preocupación de demostrar que lo deportivo no implica lo superficial, tomar las cosas deportivamente (enunciado del argot popular), sino, al contrario, requiere una revisión que dé importancia al mito como origen de las formas éticas y al arte como expresión estética que permite el estímulo del cuerpo, como principio importante de la actividad física.

En pedagogía, el aporte clásico de 1933, desarrollado por Werner Jaeger (2010), sobre la centralidad del cuerpo y el movimiento en la adquisición de los saberes sensoriales y teóricos del mundo desde la reconstrucción de la paideia griega, le da paso a la disertación de Ernest Cassirer (1984) sobre la esencia y efecto del concepto de símbolo, en la cual se analizan tres formas particulares: el mito, la estética-arte y el lenguaje. Con base en la evolución y desarrollo de cada sistema de signos e imágenes, el autor reproduce un acercamiento al concepto de la forma simbólica de la siguiente manera: "Toda energía del espíritu en cuya virtud en contenido espiritual de significado es vinculado a un signo sensible concreto y le es atribuido interiormente" (p. 163).

En la forma simbólica del mito, se halla la evolución de sus signos, la elaboración de artefactos y de objetos que podemos llamar de fe, aunque Cassirer los denomine vehículos de fuerza religiosa, donde su transformación y cambio sea la evolución de su significado, la cruz de Cristo de hoy ha cambiado significativamente en relación con la concepción medieval. Para pasar al lenguaje, formularemos la relación que existe en el mito como eje de la función ética con el siguiente esquema:

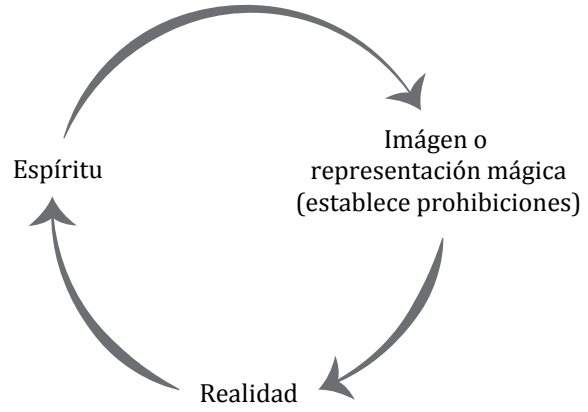

Figura 1. El mito en la función ética con base en Cassirer.

"El lenguaje se vale del sonido, el ritmo y el signo para servir al espíritu” (p. 163). Con esta afirmación de Cassirer y la triangulación anterior, podemos referir que cuando el signo se adapta al objeto establece la relación a manera de vidrio o pantalla entre nosotros y la realidad, es decir, que imagen y signo se introducen entre el individuo y su entorno.

El valor de analizar dicha relación se produce en los esquemas de creencias religiosos que atraviesan las prácticas y vivencias deportivas (jugadores de fútbol que se arrodillan y persignan después de un gol, el marketing iconográfico de las figuras de los santos con los equipos de fútbol) prácticas y formas de pensar que implican actos de comunicación de la experiencia ética, la cual se define en el fluir de los significados e interpretaciones, el aire en el que se transportan y perviven a través de las transformaciones de los sistemas lingüísticos-semióticos y las configuraciones subjetivas, allí es donde se aloja el sustrato de la función ética, por cuanto es parte del lenguaje y constituye significados a través de los cuales se procesan los actos de los seres humanos.

"La palabra no es copia del objeto, sino de la imagen de este engendrada en el alma" (Cassirer, 1984, p. 163). El signo reproduce al objeto con la fidelidad que le otorga la interpretación de cada sujeto, la relación entre lo producido y lo captado cobra vigencia, el Alter y el Ego propuestos por Luhmann (1998) se resignifican con cada intercambio simbólico en el lenguaje como maremagno comunicativo; de esta forma, las nociones que posibilitan la convivencia entre los sujetos están reguladas por sistemas simbólicos tan amplios como la religión y la educación, dos polos que generan no solo normas, sino estilos de vida a nivel social. 
La estética-arte es la expresión de los anhelos de sublimación y perfección del alma humana. Para Cassirer, arte es la comunicación de sentido y significación desde lo espiritual hacia lo material. La convicción de la creatividad que es la fortaleza del hombre para generar o plasmar sus sentimientos y sus sensaciones en la realidad, la reproducción de lo psíquico y su versión sobre el plano de los otros.

\section{Las formas del sentido común en la ética}

Lo común de toda la humanidad, el dominio de todos los que habitan y construyen sociedades, la interrelación directa de unos objetos con otros y los rasgos que marcan las diferencias entre los grupos se insertan en lenguajes y simbolismos que se socializan y comprenden en el tejido heterogéneo de la vida humana. Allí nace el sentido común como sistema social. Para Clifford Geertz (1994), se parte de un conjunto relativamente organizado de pensamiento especulativo que da origen a un cierto catálogo de realidades inmanentes a la naturaleza tan concluyentes que se imponen en cualquier mente lo suficientemente esclarecida para aceptarlas.

Así como la ideología se basa en la pasión, el sentido común constituye su andamiaje en la experiencia de la vida misma, se tiene sentido común cuando se actúa y se afronta la cotidianidad de una forma eficaz -se podría mirar la racionalidad práctica en Aristóteles- al resolver las formas de desarrollo de las personas y los objetos que convergen en los espacios. En ese ámbito relacional, trasciende el sentido común, establece sus redes en las acciones de los hombres y las actitudes que afrontan frente a los acontecimientos que impone la vida, desde el desarrollo del cuerpo hasta la dimensión espiritual, el sentido común se impone a los individuos.

Un ejemplo de ello lo podemos situar en la cultura fit$n e s s^{2}$, que hoy impone una lectura y acción diferente del cuerpo masculino y femenino a través de las prácticas saludables, las cuales se promocionan desde las imágenes de gente físicamente sana haciendo actividad física,

2 Como se le ha denominado en el vocablo anglosajón que representa la cultura de la estética corporal en los imaginarios de buena salud y armonía. Tendencias que surgen en gran medida por el impacto socioeconómico de gran escala en las economías globales por sobre carga (sujetos- costos) de los sistemas de salud por enfermedades de tratamiento crónico producto de deficiencias en el mantenimiento de la condición física como la diabetes, la hipertensión y la obesidad, las cuales llevaron a finales de la década de 1990 a la OMS a trabajar por la prevención como medida de control de estos fenómenos a través de las prácticas saludables. así como la venta de artículos deportivos, fenómenos y festivales mediáticos como el Zumba Fitness Concert ${ }^{3}$, así como la inmensa red de espacios de entrenamiento como los gimnasios, que hoy son complejos de salud donde se encuentran fisioterapeutas, médicos deportólogos y educadores físicos con la misión de coproducir cuerpos saludables.

En la cotidianidad se desenvuelven las relaciones del sentido: desde los mitos del cuerpo en actividad (cuando dicen que los fisiculturistas tienen el pene pequeño, o de las mujeres pesistas que son lesbianas por ser musculosas) hasta las costumbres y los dichos más sencillos son el resultado o el producto de la evolución de los sistemas y las significaciones, con Geertz (1994): "Los hombres levantan los diques de sus creencias más necesarias con cualquier barro que puedan encontrar" (p.101). Con los elementos que se recrean en cada ámbito, los grupos constituyen las redes de sentido y establecen los roles que deben desempeñar en cada caso o momento la formación desde el mito que da pie a lo autoritario en la ética por cuanto se da una función sobrenatural del poder en los grupos.

La temporalidad atraviesa al sentido, se va revalorando $\mathrm{y}$ transformando en sus formas del lenguaje sin perder sus referentes, evoluciona con los ritmos y las definiciones que se han construido por los hombres, el dominio de lo popular es la esencia donde se mueven intenciones $\mathrm{y}$ artefactos.

Existe una forma elemental de construcciones culturales de conocimientos que conducen a conclusiones y rasgos de la moral dentro de un contexto específico, es aquella en la que el ser humano concibe el mundo, lo entiende y actúa en él, este conjunto de pensamiento organizado es llamado sentido común y el fundamento de su teoría es la existencia en sí, el mundo es su dominio.

Para realizar el análisis del sentido común, comprendiendo este como la facultad que en general las personas tienen de juzgar razonablemente las cosas o la interpretación de las inmediateces de la experiencia, la cual está construida históricamente y sujeta a pautas, es necesario diferenciarla de aquello que se aprende

\footnotetext{
3 Evento promovido por el bailarín y coreógrafo colombiano Beto Pérez, quien diseñó hacia 1990 el programa de acondicionamiento físico Zumba, el cual trabaja la idea de los aeróbicos como un ritmo de vida, en el cual se reúnen diversión goce y salud (Bauman, 2016).
} 
de manera imparcial, y asimilarla, como unos juicios y ordenamientos sustentados en una sabiduría mundana o coloquial.

Este análisis pretende demostrar que el sentido común en la función ética puede someterse a examen y lectura, siendo distinto de una sociedad a otra, residiendo en un sistema cultural que encuentra eco en algunos de los regímenes filosóficos modernos y más en los posmodernos (Lyotard, 2009; Vattimo, 1990; Han, 2013) como idea fundadora a pesar de ser en sí mismo problemático y profundo, al reconocer la diferencia de aprendizaje a los que acceden pueblos extrayendo conclusiones diferentes a las nuestras de una misma experiencia, siendo la necesidad de representar el mundo de forma diferente.

El marco del deporte y la cultura física en el que se apuesta la reflexión de la función ética y el sentido común como nociones problemáticas implicará necesariamente la interpretación del contenido inmediato de la experiencia subjetiva, asociando cada vivencia de dicho contexto al marco general histórico en el que se desarrolló, generando una concepción del mundo de sentido que es así, entonces, una manifestación empírica cotidiana, por ejemplo: un sector del deporte (como los que integran los de alto rendimiento y seleccionados deportivos nacionales e internacionales) trascenderá el contenido y la noción de corrupción o idoneidad por unas reflexiones que guían hacia el sentido común de situaciones específicas (como el doping), entonces, en dicho lugar, el sentido común de los deportistas de alto rendimiento, asegurarían que se fundamentaría o habría que mirar la relación entre la ética-estética de la función física, diferente de la responsabilidad social, la cual estaría sobre los réditos simbólicos y culturales que un deportista implicado o no en un caso ético pueda representar para la comunidad que se ve simbolizada en su accionar deportivo (casos de doping como el de la ciclista María Luisa Calle o de actos de violencia hacía la mujer como los del futbolista Pablo Armero).

Así, las presunciones que un sujeto tiene es lo que se podría llamar el sentido común, y no la libertad de propensiones de su mente, la comprensión de los hechos será hecha siempre por los hombres, sujetos al diálogo de la experiencia de sí con su contexto, el cual se verá sometido, a su vez, a la construcción intersubjetiva e histórica del mundo social. Conocimientos y saberes que al encontrarse frente a los códigos de convivencia emanados por las instituciones sociales resuelven dar a la norma la posibilidad de totalizar sobre los espacios y los sujetos que se mantienen al interior de los mismos e interactúan. Allí nace la regulación: en la mediación racional entre los hechos y la función ética.

\section{IMAGINARIO DE LA FUNCIÓN ÉTICA DEL ADMINISTRADOR DEPORTIVO EN LAS INSTITUCIONES LIGADAS AL SECTOR}

Después de la anterior aproximación teórica, es interesante mirar la relación directa que se establece entre la función ética como agente de dialogo del sentido común con la norma y la administración deportiva. En primer lugar, la ética aparece como contenido obligatorio de todas las carreras profesionales gracias a la Ley 80 de 1980, artículo 39, esta decisión que parece ya de tiempo atrás ha tenido una serie de repercusiones que ponen en discusión la fundamentación y los ejes temáticos sobre los cuales debe versar. Precisamente, desde las universidades como instituciones formadoras viene una responsabilidad sobre una serie de derroteros que permitan consolidar profesionales que asuman posturas racionales y argumentadas para resolver los asuntos de la vida diaria a nivel profesional y personal.

Hablar de la administración, la gestión y el control deportivo es cruzar hacia un territorio inhóspito en el discurso, más cuando se hace referencia a la ética y su relación directamente social y profesional. Debido a esta razón, se pretende abordar una serie de conceptos y mirar su cuestión simbólica. Se trata de mirar el imaginario que se tiene con respecto a varias nociones y conceptos que se relacionan con el desarrollo de lo la función ética en la gestión, el control, la auditoría y administración del deporte, por tal razón se presenta, a guisa de glosario, una serie de nociones y sus significaciones.

Desde el Estado, el Sistema Nacional del Deporte ha planteado un concepto oficial de la ética deportiva:

La práctica del deporte, la recreación y el aprovechamiento del tiempo libre preservará la sana competición, pundonor y respeto a las normas y reglamentos de tales actividades. Los organismos deportivos y los participantes en las distintas prácticas deportivas deben acoger los regímenes disciplinarios que le sean propios, sin prejuicios de las responsabilidades legales pertinentes. (Ley $181 \mathrm{de}$ 1995, Gracia, 2000, p. 57). 
Esta noción desemboca en las formas de la deportividad, la cual es concebida por el Consejo Superior de Deporte de Galicia (España) como concepción del deporte que trasciende del puro cumplimiento de las reglas deportivas para situarse en un entorno de respeto, caballerosidad y consideración del adversario (p. 57). Se tiene entonces una aplicación de las formas sociológicas a la especificidad del deporte, donde el acto como función se desenvuelve en la actividad física y la competición. Por otro lado, en el caso de la administración y el control, se liga íntimamente con las definiciones conceptualizadas para la administración de empresas como tal, por cuanto se deriva en el ejercicio de la gestión pública y la gerencia de lo privado.

Igual sentido interpretativo se le puede dar a la moral, en razón que se ha denominado su función como conjunto de normas, sistemas simbólicos que interactúan aplicados al deportista y a quienes intervienen en el sector del deporte y la recreación. En los marcos de la psicología del deporte, se ha abordado en relación con la actividad física y la competición un tipo de razonamiento que se puede engranar en la experiencia de Erich Fromm (1997) (plasmada en Ética y psicoanálisis), por cuanto la visión y función de lo ético se ubica en el carácter del deportista o de quien interviene en el escenario deportivo. La personalidad del individuo como condición humana y condicionante de las relaciones intersubjetivas entre sí, de tal manera que cuando se habla de la gestión y regulación de recursos humanos y la administración, se establece un lazo semejante, es decir, que la base de las acciones del administrador deportivo en relación a su conciencia-acto pueden perfilarse desde su condición humana y personalidad.

Sin embargo, el psicólogo Hiram Valdés (1998) propone que dentro del deporte las cuestiones de conciencia y ética se someten a la variabilidad de las condiciones de los diferentes sectores y modalidades deportivas:

Los ideales y las normas morales: Bastante descuidados en el deporte, es aquí donde pueden encontrarse respuestas a los fenómenos de agresión que tanto ocupan últimamente. Uno de los aspectos más interesantes está en el carácter velozmente cambiante de las normas deportivas y su relación con la reglamentación y la táctica en cada deporte. La interpretación sociológica, según la cual toda trasgresión reglamentaria implica hostilidad, es altamente discutible si no se vincula con lo anteriormente citado. (p. 213).
Personalidad, carácter, condición humana son formas de denominar la función ética de los individuos con respecto a sus actividades en la cotidianidad del campo deportivo y fuera de él. Variables de juicio sobre los acontecimientos y las circunstancias que los enmarcan, obras en escenarios, actuaciones donde hay factores que afectan y agentes afectados. Concebir la cuestión de la moral y las normas de tal modo que la convivencia no sea una obligación, sino un modo de vida.

Frente a esta serie de cuestiones a nivel nacional se ha implementado el régimen disciplinario, donde se regulan las infracciones que involucran las formas de desarrollo del deporte desde todos los enfoques del sector deportivo:

\section{CONGRESO DE LA REPÚBLICA LEY NÚMERO 49 DE 1993}

(Marzo 4)

"Por la cual se establece el régimen disciplinario en el deporte".

El Congreso de Colombia,

DECRETA:

ART. 1-Objeto del régimen disciplinario. El régimen disciplinario previsto en esta ley, tiene por objeto preservar la ética, los principios, el decoro y la disciplina que rigen la actividad deportiva y a la vez asegurar el cumplimiento de las reglas de juego o competición y las normas deportivas generales.

ART. 2o-Campo de aplicación. El campo de aplicación del régimen disciplinario en el deporte, para los efectos de la presente ley, se extiende a las infracciones de las reglas de juego o competición y normas generales deportivas, tipificadas en el Decreto 2845 de 1984, en esta ley y en las disposiciones reglamentarias de estas normas y en las estatutarias de los clubes deportivos, ligas, divisiones profesionales y federaciones deportivas colombianas, cuando se trate de actividades o competiciones de carácter nacional e internacional o afecte a deportistas, dirigentes, personal técnico, científico, auxiliar y de juzgamiento que participen en ellas.

ART. 3o-Conceptos de infracción. Son infracciones de las reglas de juego o competición las acciones $u$ omisiones que, durante el curso del juego o competición, vulneren, impidan o perturben su normal desarrollo y son infracciones a las normas generales deportivas las demás acciones u omisiones que sean contrarias a lo dispuesto por dichas normas, en especial el Decreto 2845 de 1984 y las que lo reglamenten. 
ART. 4o-Responsabilidad disciplinaria. La responsabilidad emanada de la acción disciplinaria contra los sometidos al régimen disciplinario en el deporte, es independiente de la responsabilidad penal, civil o administrativa que dicha acción pueda originar.

ART. 5o-Previa definición de la infracción y de la sanción disciplinaria. Ninguno de los sometidos al régimen disciplinario podrá ser sancionado por un hecho que no haya sido definido previamente como infracción disciplinaria, ni sometido a sanción de esta naturaleza que no haya sido establecida por disposición anterior a la comisión de la infracción que se sanciona.

ART. 6-_Derecho a la defensa. El trámite de instrucción y resolución que deben adelantar los tribunales deportivos, el tribunal nacional del deporte y las autoridades disciplinarias, estará basado en el principio de defensa, de audiencia del acusado, favorabilidad y de contradicción de la prueba.

ART. 7ㅇ-Potestad disciplinaria. La potestad disciplinaria atribuye a sus titulares legítimos la posibilidad de reprimir o sancionar a los sometidos al régimen disciplinario en deporte, según sus respectivas competencias (Ley 49 de 1993).

El texto - del cual se presentan algunos ítems- comprende 57 artículos encaminados a plantear una serie de claridades sobre las infracciones y patrones a seguir entre los individuos y sus respectivas afiliaciones con el sector deportivo, en lo referente a su campo específico: pedagógico, de ligas, clubes, comités, escuelas de formación, institutos descentralizados, etc.

\section{Cómo se percibe el imaginario de la función ética}

A continuación se presentan los resultados de una encuesta que fue aplicada en personas que intervienen en el campo deportivo ${ }^{4}$. Aunque numéricamente la muestra no se vea significativa, para este trabajo significaba un sondeo entre estudiantes activos y egresados en ejercicio que constituyen el capital social de impacto de programas académicos como el proyecto de Administración Deportiva en la Universidad Distrital Francisco José de Caldas, por ejemplo, de allí que esta medición permite ahondar el impacto de los procesos de formación y el desarrollo de las habilidades en el plano del trabajo tanto de campo como de su desenvolvimiento profesional.

Para la muestra, se diseñó un cuestionario de veinte preguntas de tipo abierto que giraba sobre cuatro ejes fundamentales, donde se busca detectar las significaciones que están fluyendo entre los encuestados, y un último numeral que busca la asociación de términos vinculados a conceptos del deporte que se fusionan con la administración, la gestión y el control.

Para el desenvolvimiento de las categorías, se toma en cuenta la frecuencia que se despliega en cada una de la siguiente manera:

Tabla 1. Categorías y frecuencias del sondeo.

\begin{tabular}{|l|c|c|}
\hline \multicolumn{1}{|c|}{ Categoría } & Frecuencia & $\begin{array}{c}\text { Total de } \\
\text { porcentajes }\end{array}$ \\
\hline Funciones éticas & 43 & $45 \%$ \\
\hline Ética y deporte & 25 & $25 \%$ \\
\hline $\begin{array}{l}\text { Administración } \\
\text { deportiva }\end{array}$ & 32 & $30 \%$ \\
\hline Totales & 100 & $100 \%$ \\
\hline
\end{tabular}

Fuente: elaboración propia

A partir de este formato, se hizo la pesquisa con base en una organización radial de acuerdo con las frecuencias sobre lo que se piensa de la administración deportiva en sus elementos de control, cómo se comprende la significación ética y hacia dónde están encaminadas las expectativas de los sujetos que hicieron este ejercicio de reflexión.

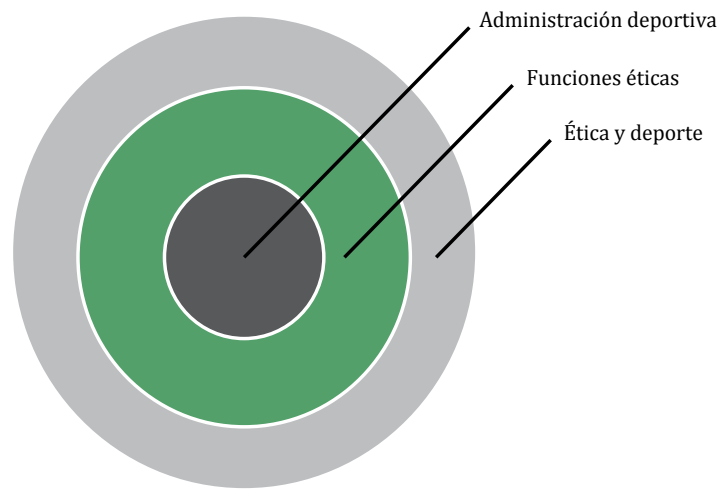

Figura 3. Organización radial del orden imaginario en las referencias del sondeo.

Fuente: elaboración propia
4 Fue realizada con cien personas entre estudiantes de administración deportiva y egresados de esta profesión, quienes se desempeñan en cargos administrativos o de gestión en el IDRD y el sector privado en gimnasios y clubes deportivos. 


\section{La ética como concepto imaginario}

Frente a la cuestión sobre cómo se define la ética, se encontró que lo que prevalece en la imaginación en relación con este concepto es la influencia y acción de los valores. Para la mayoría de encuestados (65\%), la importancia de lo ético estaba cimentado en los valores con que actúa el individuo en la sociedad. En segundo lugar, determinaron que la importancia radicaba en revisar las formas del comportamiento frente a las situaciones y las circunstancias. Esta respuesta da pie a la interpretación desde el contexto educativo, tradicionalmente se ha llevado el ejercicio de los valores como punto crucial de la formación humana, el valor se interpreta como esa cualidad que se sujeta a la actitud del individuo con respecto a su acto social, es decir, que se reconoce como atributo o característica legítima y aceptada por un grupo como útil para la convivencia.

A su vez, las formas de comportamiento implican la proyección de las condiciones actitudinales y aptitudinales, recordando al clásico Herman Nohl (1952), en el panorama de la interacción humana están relacionados tanto los principios del nivel biológico, los cuales plantean el gozo de los sentidos, como los del nivel anímico y creador, donde se resaltan aquellas cualidades propias del espíritu, "lo que enaltece el alma" la armonía y la idealización de lo moral (p. 66). El acto como construcción individual se halla en los sistemas de valores, los cuales son simbólicos y su existencia solo tiene sentido cuando hay referente:

Los valores no existen por sí mismos, al menos en este mundo: necesitan un depositario en quien descansar. Se nos aparecen como meras cualidades de esos depositarios: la belleza de un cuadro, la elegancia de un vestido, la utilidad de una herramienta. (Frondizi, 1958, p. 11).

Desde los autores antiguos se encuentra que la sociedad otorga la valoración a las acciones, y de acuerdo con tal juicio se observan las realizaciones del hombre.

Valores, comportamientos y por último se mencionó el acto de la decisión, la elección entre lo debido y lo prohibido, la oportunidad de distinguir un camino del otro y saber escoger qué acción es la más indicada, la ética observada como un conjunto de valores y normas.

\section{La aplicación de lo ético al deporte}

La respuesta a la cuestión sobre cómo aplicaría el concepto de ética al deporte deriva de la anterior, por cuanto se le pidió a los encuestados contestar con base en la respuesta que implicaba definir la ética. Así que, en cierta forma, siguiendo una línea de argumentación, los participantes manifestaron la necesidad de aplicar la fundamentación de los valores, pero adaptados al deporte y su gestión y control, contextualizando las situaciones a resolver al interior de las escuelas de formación, los clubes y ligas, en todo espacio destinado para estos fines lúdicos.

Otro elemento esencial aportado por el consenso de los integrantes del cuestionario estuvo en la importancia dada al juego limpio (73\% de la muestra) como el respeto al adversario y a las normas que reglamentan los juegos, independiente de la modalidad o nivel de profesionalismo. Junto con esta necesidad dentro de los distintos deportes, se sobrevino el planteamiento de una observación de los comportamientos de los distintos actores que se involucran en el sector, desde el jugador hasta el funcionario, una vez más vuelve a ser el acto el centro de la visión de las funciones de lo ético.

\section{El concepto de administración deportiva}

En la visión tomada en este instrumento a través de la inquietud acerca de la definición de la administración deportiva (en adelante $\mathrm{AD}$ ), se pudo evidenciar que existen tres versiones muy acentuadas sobre el concepto: la primera habla de la existencia de la AD como una rama de la administración de empresas encargada del deporte y una disciplina enfocada en los fenómenos del mundo lúdico, campo que se define desde la gestión de las calidades de las entidades y cuerpos colegiados involucrados en la recreación (45\% de la muestra).

En segundo lugar, se reconoce como un conjunto de acciones, realizaciones e intenciones de manejar y organizar, la gestión y administración del deporte y la recreación, en función del bienestar de las comunidades y los grupos sociales afectados por un desequilibrio en la calidad de vida, niveles de esparcimiento y utilización del tiempo libre (33\%). Se piensa en una ciencia de control y dinamización de la gestión empresarial a nivel deportivo donde no solo se dirija una serie de recursos financieros, sino donde se trabaja directamente con capital social (22\%). 
Por último, es importante resaltar el papel innovador que se le otorga a la AD como alternativa no solo de negocios, sino de proyección laboral, una tercera vía en medio del mecanicismo cotidiano de las visiones sobre empresa de la sociedad actual, una forma distinta tanto de propuesta empresarial como de medio de regular las relaciones que se dan entre las entidades que administran el deporte en todas sus dimensiones, una oportunidad de especializar el conocimiento y dejar el sentido amateur de dirigir por una elaboración concreta desde la teoría y la práctica enfocada académicamente.

El sentido de la ética del administrador deportivo y las normas básicas para su desarrollo

La fusión de los dos ítems que tocan a la proyección de una ética para el administrador deportivo permite consolidar los elementos que encaminan el ejercicio de una ética con dicho enfoque; se ha contemplado la forma de proceder de acuerdo con los códigos empresariales cimentados sobre la administración en general, tanto en la gestión y control del sector público -la cual se caracteriza por un conjunto de normas específico- y la del privado, la cual está sujeta a las referencias de directivos y propietarios sobre las infraestructuras, recursos económicos y humanos.

En el discurso sobre el tema, se halla un elemento central: el concepto de bienestar que prevalece en el desarrollo ético de la empresa deportiva, la función del deporte como forma de desarrollo integral del individuo, factor determinante de una armonía en las relaciones sociales en que se puede canalizar una serie de expresiones negativas, como son la violencia y en parte el sedentarismo que deteriora la salud de los ciudadanos, optimizando los niveles y la calidad de vida donde se proyectan la recreación y el deporte.

Frente a este ejercicio de reflexión sobre el buen desempeño del profesional, se plantearon una serie de normas o pautas (el $98 \%$ de la muestra) que ayudarían al ejercicio responsable de la función social, sin embargo, la influencia de la visión que sujeta la ética a los valores hizo que se confundieran la norma y los códigos con dichas calidades humanas; gran parte de los estudiantes, cuando se les preguntó: ¿Qué normas básicas puede tener una ética del administrador deportivo? Respondieron con valores o cualidades como el respeto, tolerancia, amabilidad, etc. A pesar de esta serie de confusiones conceptuales, varios estudiantes dieron las siguientes normas como posibles ítems de un código:

- El deporte y el bienestar de las comunidades deben estar por encima de lo material y el bien propio.

- Debe haber una discreción profesional a fin de respetar la integridad moral de un trabajador frente al grupo en caso de amonestación bajo los mecanismos del control y la gestión.

- La protección y respeto hacia la experiencia deportiva.

- Generar siempre acciones que beneficien el deporte.

- Conocer el deporte en todas sus áreas y la actividad física.

- Usar adecuadamente el tiempo libre.

- Ser ejemplar en el cuidado físico.

Finalmente, la edad del $60 \%$ de los encuestados se ubica entre los 20 y los 30 años y gran parte de los encuestados se encuentra trabajando en diferentes sectores productivos del deporte, también hay estudiantes que laboran en instituciones promotoras del deporte y que evidencian en su cotidianidad cómo se desarrolla el conjunto de relaciones sociales que allí acontecen.

\section{Tabla de conceptos-asociaciones imaginarias de la administración deportiva}

El último ejercicio consistió en realizar una serie de asociaciones sobre unos términos planteados por el instrumento: las palabras estaban relacionadas con el deporte y la administración -donde se incluyen elementos del control y la gestión-, ocho ejes que, al cotejar los resultados, dieron como resultado un conjunto de veinte asociaciones por cada uno, teniendo en cuenta que se repetían; estas repeticiones sirvieron para mirar las asociaciones que prevalecían sobre las otras, determinando los niveles significativos que definen los conceptos propuestos por la encuesta.

Las asociaciones plasmadas, situadas en el examen de la representación, permiten mirar los elementos relevantes del imaginario de un concepto (al respecto se puede 
revisar la metodología de mapas de asociaciones en Jean Claude Abric, 2001). Así (tabla 2) se comienza de las más importantes a las de menor regularidad, teniendo en cuenta el número de veces en que fueron señaladas:

Libertad, salud, descanso y esparcimiento, entre otras palabras, presentan cómo el mecanismo de representación se vale de la multiplicidad de lo interpretativo para definir uno o varios conceptos con la misma expresión. Por fuera quedaron muchas implicaciones que resultaron irregulares dentro de la muestra (entre el 1\% y el $3 \%$ ). De esta manera, se presenta (tabla 2) lo que se resaltó en el proceso de asociación, entre ellos términos como control o auditoria en relación con la administración (señal de una falta de información más específica del tema) no fueron muy sugeridos.

Por medio de la anterior representación, se pueden mirar las concepciones bajo las cuales se conjugan los términos que influyen en el deporte y su relación administrativa y de gestión. En este universo relacional, se sumerge la función ética y su relación como establecimiento simbólico entre los individuos y la realidad. Se da cuenta de una instantánea del imaginario con el cual los profesionales de la administración del deporte abordan el campo de trabajo y los retos de pensar las relaciones entre cuerpo, deporte y sociedad. Este muestreo es apenas un abreboca de las posibilidades que hay de reflexión frente al fenómeno, y de paso una invitación a continuar con el tema frente a una sociedad cada vez más crítica en las relaciones de los valores y el deporte como fórmulas de vida.

\section{CONSIDERACIÓN FINAL}

Como se enunció en un principio, hablar de la función ética y el sentido común en la administración deportiva es evocar un conjunto de diálogos que se presentan al interior de los saberes y su desarrollo humano. El interés del presente texto fue hacer un acercamiento a lo que se piensa en relación con el tema desde las posiciones teóricas y la perspectiva de lo imaginario de los estudiantes y profesionales que ejercen profesionalmente desde lo administrativo-físico en el deporte.

En Colombia, se ha planteado la cuestión ética desde los aspectos que refieren a la problemática de la corrupción y sus manifestaciones en las formas del Estado y el sector privado. Tomar conciencia frente a esta serie de fenómenos permite meditar sobre el papel ético del profesional en los avatares de la contemporaneidad;

Tabla 2. Asociaciones a conceptos propios de la administración deportiva y su rango de frecuencia en orden de mayor a menor.

\begin{tabular}{|c|c|c|c|}
\hline $\begin{array}{c}\text { Deporte } \\
\text { De } 60 \text { a } 30 \\
\end{array}$ & $\begin{array}{c}\text { Ocio } \\
\text { De } 60 \text { a } 40 \\
\end{array}$ & $\begin{array}{c}\text { Tiempo libre } \\
\text { De } 80 \text { a } 30\end{array}$ & $\begin{array}{c}\text { Actividad } \\
\text { física De } 90 \text { a } 30\end{array}$ \\
\hline $\begin{array}{l}\text { Actividad } \\
\text { Salud } \\
\text { Competencia } \\
\text { Formación } \\
\text { Disciplina } \\
\text { Reglas }\end{array}$ & $\begin{array}{l}\text { Descanso } \\
\text { Libertad } \\
\text { Esparcimiento } \\
\text { Actividad } \\
\text { Placer }\end{array}$ & $\begin{array}{l}\text { Aprovechamiento } \\
\text { Libertad } \\
\text { Descanso } \\
\text { Esparcimiento }\end{array}$ & $\begin{array}{l}\text { Movimiento } \\
\text { Salud } \\
\text { Ejercicios } \\
\text { Deporte }\end{array}$ \\
\hline $\begin{array}{c}\text { Recreación } \\
\text { De } 50 \text { a } 10\end{array}$ & $\begin{array}{c}\text { Juego } \\
\text { De } 30 \text { a } 10\end{array}$ & $\begin{array}{c}\text { Administración } \\
\text { De } 90 \text { a } 30\end{array}$ & $\begin{array}{c}\text { Lúdica } \\
\text { De } 90 \text { a } 20\end{array}$ \\
\hline $\begin{array}{l}\text { Distracción } \\
\text { Diversión } \\
\text { Juego } \\
\text { Creación } \\
\text { Distención }\end{array}$ & $\begin{array}{l}\text { Diversión } \\
\text { Esparcimiento } \\
\text { Alegría } \\
\text { Imaginación }\end{array}$ & $\begin{array}{l}\text { Organización } \\
\text { Manejo } \\
\text { Gestión } \\
\text { Planeación } \\
\text { Dirección } \\
\text { Orden } \\
\text { Eficacia }\end{array}$ & $\begin{array}{l}\text { Diversión } \\
\text { Juego } \\
\text { Entretenimiento } \\
\text { Aprendizaje } \\
\text { Pedagogía } \\
\text { Cuerpo }\end{array}$ \\
\hline
\end{tabular}


procesos de niveles macro como la Globalización y la Mundialización de la economía plantean derroteros referenciales a donde debe apuntar el debate ético, el juicio sobre la violencia y los descalabros de la corrupción recuerdan una frase de Cesare Beccaria presentada por el magistrado italiano Paolo Ielo: "El conocimiento de que no exista un palmo de tierra que perdone los delitos sería el mejor modo para evitarlos" (Ielo, 2000, p. 86).

Cerrar los ojos a modo conveniente de no pensar en lo que ocurre en la sociedad actual, donde se deja muchas veces el ejercicio de la ética a un inventario de autores e ideas que no lleva al ciudadano más que a llamarlos de vez en cuando para citar una frase, mientras en su interior quedó anclado el imaginario del refrán y de la cotidianidad enmarcada por los juicios divididos de morales judeocristianas reinterpretadas donde se producen sujetos amorales e inmorales.

Este artículo se permite provocar una reflexión sobre los elementos constitutivos de lo humano en la administración del sector del deporte y la actividad física, la visión interdisciplinar y teórica es un abreboca que busca desembocar en la reflexión sobre los procesos de normatividad que se piensan en la gestión de la empresa deportiva actual.

Concluyendo, como se enuncia a través de Borges, "el orden inferior es un espejo del orden superior; las formas de la tierra corresponden a las formas del cielo; las manchas de la piel son un mapa de las incorruptibles constelaciones" (1995, p. 62), las obras de los hombres son reflejo de su propio raigambre, la sociedad que les dio a luz y les predijo su destino, a veces se toman los temas de la ética y el deporte deportivamente, odioso termino que arguye que el deporte no es riguroso, pero que actualmente está de capa caída como dicho frente a las nuevas generaciones de investigadores, administradores y deportistas que, preocupados por el desarrollo de la ciencia y la práctica han repotenciado las formas de concebir lo lúdico y lo deportivo, hoy la ética interviene a favor de una mayor conciencia en la gestión y administración de este sector social, desde lo interdisciplinario y escuchando las voces de las humanidades, el deporte y el imaginario colectivo.

\section{REFERENCIAS}

Abric, J. (2001). Prácticas sociales y representaciones. México: Coyoacán Ediciones.

Bauman, S. (2016). Zumba y el sueño americano de Beto Pérez. Magazine Hispanos About en Español. Recuperado de: http://hispanos.about.com/od/ Personajes/a/Latinos-Destacados-El-Sue-NoAmericano-De-Beto-Perez.htm

Borges, J. (1995). Artificios. Madrid: Alianza Cien.

Cassirer, E. (1983). Antropología filosófica. México: FCE.

Cassirer, E. (1984). Esencia y efecto del concepto de Símbolo. México: Fondo de Cultura Económica.

Castoriadis, C. (1989). Institución imaginaria de la sociedad. Barcelona: Tusquets.

Castoriadis, C. (2003). La pluralidad de los imaginarios sociales de la modernidad. Barcelona: Anthropos.

Durand, G. (2000). Lo imaginario. Barcelona: Ediciones del Bronce.

Fromm, E. (1997). Ética y psicoanálisis. México: Spes.

Frondizi, R. (1958). ¿Qué son los valores? México: Fondo de Cultura Económica.

Geertz, C. (1994). Conocimiento local: Ensayos sobre la interpretación de las culturas. Barcelona: Paidós.

Gracia, A. (2000). ¿Qué es ética deportiva? Y ¿qué es moral deportiva? KINESIS Revista de Educación Física y Deporte. Armenia: Editorial Kinesis.

Ielo, P. (2000). Sociedad civil frente a la corrupción en un mundo globalizado. Memorias del foro internacional Estado y Sociedad frente a la corrupción en un mundo globalizado. Bogotá: Auditoria general de la Republica.

Jaeger, W. (2010). Paideia: los ideales de la cultura griega. México: Fondo de Cultura económica.

Luhman, N. (1998). Sistemas sociales. Lineamientos para una teoría general. Barcelona: Antrhopos.

Moscovici, S. (1985). Psicología social I y II. Barcelona: Paidós.

Nohl, H. (1952). Introducción a la ética. México: Fondo de Cultura económica.

Ricoeur, P. (1996). El sí mismo como otro. México: Siglo XXI.

Riera, J. (1998). Fundamentos del aprendizaje de la técnica y la táctica deportivas. Barcelona: INDE Publicaciones.

Valdes, C. (1998). Personalidad y deporte. Barcelona: INDE Publicaiones.

Verón, E. (1996). La semiosis social. Barcelona: Gedisa. 